\title{
Association of RGS20 expression with the progression and prognosis of renal cell carcinoma
}

\author{
LIN JIANG $^{1}$, JIANGWEI SHEN ${ }^{1}$, NING ZHANG ${ }^{1}$, YONGCHAO HE ${ }^{1}$ and ZHENGHUA WAN ${ }^{2}$ \\ ${ }^{1}$ Department of Urology, Caoxian People's Hospital, Heze, Shandong 274400; ${ }^{2}$ Department of Urology, \\ The Fifth Hospital of Xiamen, Xiamen, Fujian 361101, P.R. China
}

Received January 9, 2021; Accepted April 28, 2021

DOI: $10.3892 /$ ol.2021.12904

\begin{abstract}
Regulator of G protein signaling 20 (RGS20) has been shown to be highly expressed in various types of cancer. The present study aimed to investigate the effects of RGS20 in patients with renal cell carcinoma (RCC) and in RCC cells. Bioinformatics analysis was performed to analyze the role of RGS20 in RCC. Quantitative PCR and western blotting were used to determine the mRNA and protein expression levels of RGS20 in cells, respectively. After RGS20 inhibition, the proliferation, apoptosis, migration and invasiveness of A-498 cells were tested using MTT assay, EdU assay, propidium iodide staining, Annexin V-FITC/PI kit, wound healing assay and Transwell assay. High RGS20 expression was closely associated with the progression and immune infiltration of $\mathrm{RCC}$, and may be considered as an independent indicator of poor prognosis in RCC. After knocking down RGS20, the proliferation, migration and invasiveness of cells were impaired, the cell cycle was arrested at the $\mathrm{G}_{0} / \mathrm{G}_{1}$ phase, and the level of apoptosis was increased. In addition, the mRNA expression levels of securin, CDC20 and cyclin B1 were decreased in RGS20-knockdown cells. RGS20 expression was significantly associated with the infiltration level of activated CD4 $\mathrm{T}$ cells, type $1 \mathrm{~T}$ helper cells and activated dendritic cells. In summary, RGS20 expression was associated with RCC progression and poor prognosis; thus, it may be used to estimate the prognosis of RCC and may serve as a new potential treatment strategy for RCC.
\end{abstract}

Correspondence to: Dr Yongchao He, Department of Urology, Caoxian People's Hospital, 1 Healthy New Village, Minjiang Road, Caoxian Development Zone, Heze, Shandong 274400, P.R. China E-mail: heyongchao2005@163.com

Dr Zhenghua Wan, Department of Urology, The Fifth Hospital of Xiamen, 101 Min'an Road, Xiang'an, Xiamen, Fujian 361101, P.R. China

E-mail:1wwzh66@163.com

Key words: renal cell carcinoma, regulator of $\mathrm{G}$ protein signaling 20, poor prognosis, tumor metastasis

\section{Introduction}

Renal cell carcinoma (RCC) is one of the most common and aggressive malignant tumors of the urinary system, accounting for $2-3 \%$ of adult malignancies $(1,2)$. The incidence of kidney cancer is rising, with a worldwide mortality rate of $2 / 100,000$ in 2012, ranking 16th with regard to the mortality rate among malignant tumors (3). The number of deaths in Chinese patients with kidney cancer in 2014 was 26,000 (4). In 2018, in the United States, 65,340 people were diagnosed with RCC and 14,970 died from the disease, and by 2030, an increase in the number of RCC-associated deaths of $\geq 20 \%$ is expected, compared with that in 2007 (5,6). An early diagnosis of the disease allows patients to receive treatment timely. An accurate diagnosis of the progress of the disease can help to guide the adjuvant treatment intensity and postoperative monitoring of patients, thereby improving their clinical outcomes (7). However, the treatment strategy would be incomplete and have limited accuracy unless a molecular diversity of RCC cases, such as the combination of $\mathrm{T}$ stage, grade and patient performance status, was used to evaluate the prognosis of patients (8-10). In order to improve the classification of patients with RCC into different risk groups, molecular biomarkers should be included in the prognostic algorithm since they can capture the molecular diversity of the disease. In addition, vascular endothelial growth factor receptor inhibitors and mTOR inhibitors have been used in the treatment of RCC (11). Although patients have exhibited significant clinical responses, the therapeutic effects of these inhibitors are limited due to the drug-resistant phenotype (12). Therefore, there is an urgent need for more effective and specific treatment strategies for RCC.

Regulator of $\mathrm{G}$ protein signaling 20 (RGS20) belongs to the RZ family and is highly expressed in the brain, especially in the caudate nucleus and the temporal lobe (13-16). There is increasing evidence that increased expression levels of RGS20 are associated with the occurrence and progression of different types of cancer, including bladder cancer, breast cancer, oral squamous cell carcinoma (OSCC) and metastatic melanoma (17-20). For example, the overexpression of RGS20 increases the protein expression levels of cyclin D1, vimentin and $\mathrm{N}$-cadherin in OSCC cells, but decreases the protein expression levels of E-cadherin, indicating that RGS20 promotes epithelial-mesenchymal transformation 
and cell cycle progression in OSCC cells (17). Moreover, in bladder cancer, upregulated RGS20 expression promotes cell proliferation and migration by activating NF- $\kappa$ B signaling (20). In addition, a study has indicated that after the overexpression of RGS20 in HeLa, MDA-MB-231, H1299 and A549 cells, the abilities of the cells to aggregate, migrate, invade and adhere are enhanced, suggesting that RGS20 may promote tumor metastasis (21).

To the best of our knowledge, there are no studies on the association between RGS20 and RCC. Therefore, the present study aimed to investigate the importance and clinical significance of RGS20 in RCC.

\section{Materials and methods}

Cell lines and cell culture. The human renal epithelial cell line (HK-2) and RCC cell lines, including 786-O, A-498 and Caki-1 cells, were purchased from the American Type Culture Collection. The RCC SN12-PM6 cell line was obtained from XIAMEN Anti-HeLa Biological Technology Trade Co. Ltd. Cells were cultured at $37^{\circ} \mathrm{C}$ in a humidified atmosphere with $5 \% \mathrm{CO}_{2}$ using DMEM (Gibco; Thermo Fisher Scientific, Inc.) supplemented with 10\% FBS (Gibco; Thermo Fisher Scientific, Inc.), $100 \mathrm{U} / \mathrm{ml}$ penicillin and $100 \mathrm{U} / \mathrm{ml}$ streptomycin.

Construction of stable RGS20-knockout cell lines. The pLV-sh-puro vector was purchased from XIAMEN Anti-HeLa Biological Technology Trade Co., Ltd., and used to prepare the lentiviruses for short hairpin (sh)RGS20 (Gene ID, 8601) or scrambled control (shctrl) transfection. The corresponding primer sequences of shRNAs were designed and synthesized according to the pLV-sh-puro vector specifications (Table I).

To prepare the lentiviral particles, $9 \mu \mathrm{g}$ of shRGS20 and the suitable packaging plasmids ( $3 \mu \mathrm{g}$ of pMD2G and $6 \mu \mathrm{g}$ of pspax2) were co-transfected into $293 \mathrm{~T}$ cells (Xiamen Immocell Biotechnology Co., Ltd.) using Lipofectamine ${ }^{\circledR} 2000$ (Invitrogen; Thermo Fisher Scientific, Inc.). After 48 h, the supernatant was collected, which contained the lentivirus, and then the lentivirus was enriched and the titer was determined as described previously (22). In the presence of $8 \mu \mathrm{g} / \mathrm{ml}$ polypropylene, the lentivirus was transduced into A-498 cells at a multiplicity of infection (MOI) of 30. After $48 \mathrm{~h}$, the medium was replaced with fresh medium, and puromycin was added at a final concentration of $1.0 \mu \mathrm{g} / \mathrm{ml}$. After $72 \mathrm{~h}$, cells were collected for RGS20 expression analysis.

Quantitative PCR ( $q P C R)$. RNA was isolated from cells using an RNA isolation kit (Omega Bio-Tek, Inc.) and reverse transcribed using a HiScript II 1st Strand cDNA Synthesis kit (Vazyme Biotech Co., Ltd.) according to the manufacturer's instructions. qPCR analysis was performed using the iQ5 Real-Time PCR Detection System (Bio-Rad Laboratories, Inc.) and a ChamQ SYBR qPCR Master Mix kit (Vazyme Biotech Co., Ltd.) to determine the mRNA expression levels of the genes of interest. The thermocycling conditions of qPCR were $95^{\circ} \mathrm{C}$ for $3 \mathrm{sec}$, followed by 40 cycles at $95^{\circ} \mathrm{C}$ for $10 \mathrm{sec}$ and $60^{\circ} \mathrm{C}$ for $30 \mathrm{sec}$. The relative expression levels of genes were normalized to the $18 \mathrm{~S}$ rRNA levels using the $2^{-\Delta \Delta C \mathrm{q}}$ method (23). The primers used for $\mathrm{qPCR}$ are shown in Table II.
Western blotting. Cells were lysed in ice-cold RIPA buffer (Beyotime Institute of Biotechnology) to extract protein, and protein quantification was performed with a BCA protein concentration determination kit (Beyotime Institute of Biotechnology). A total of $20 \mu \mathrm{g}$ of protein/lane was separated via $10 \%$ SDS-PAGE. After the separation, proteins were transferred to polyvinylidene difluoride membranes. After being blocked with $5 \%$ skimmed milk in TBS-Tween $(0.05 \%$ Tween-20) buffer at $25^{\circ} \mathrm{C}$ for $1 \mathrm{~h}$, the membranes were incubated with the primary antibodies for $2 \mathrm{~h}$ at room temperature, followed by incubation with the appropriate secondary antibody for $1 \mathrm{~h}$ at room temperature. The membranes were visualized using a typically enhanced chemiluminescent kit (Thermo Fisher Scientific, Inc.). ImageJ v1.48 (National Institutes of Health) was used for densitometry. The following primary antibodies were used in the present study: RGS20 (cat. no. YN1202, 1:1,000; ImmunoWay Biotechnology Company) and GAPDH antibodies (cat. no. YM3029, 1:1,000; ImmunoWay Biotechnology Company). The secondary antibodies conjugated with horseradish peroxidase were anti-mouse IgG (cat. no. 7076; 1:2,000; Cell Signaling Technology, Inc.) and anti-rabbit IgG (cat. no. 7074; 1:2,000; Cell Signaling Technology, Inc.).

MTT assay. A-498 cells stably expressing shctrl or shRGS20 were seeded on 96-well plates at a density of 10,000 cells/well. After 24,48 or $72 \mathrm{~h}$ of culture at $37^{\circ} \mathrm{C}, 20 \mu \mathrm{l}$ of MTT $(5 \mathrm{mg} / \mathrm{ml})$ was added to each well and the cells were incubated at $37^{\circ} \mathrm{C}$ for 4 h. Subsequently, the supernatant in the wells was carefully aspirated, $150 \mu \mathrm{l}$ of DMSO was added to each well, and the cell culture plate was shaken for $10 \mathrm{~min}$ to dissolve the crystals. Subsequently, the light absorption value of each well was measured at $490 \mathrm{~nm}$ using a microplate reader (Thermo Fisher Scientific, Inc.), and the results were recorded. The cell growth curve, with time as the $\mathrm{x}$-axis and absorbance as the $\mathrm{y}$-axis, was plotted.

EdU assay. A-498 cells stably expressing shctrl or shRGS20 were seeded on 96-well plates at a density of 100,000 cells/well. After $24 \mathrm{~h}$ of culture at $37^{\circ} \mathrm{C}$, the cells were incubated at $37^{\circ} \mathrm{C}$ for $4 \mathrm{~h}$ with DMEM containing $\mathrm{EdU}(50 \mu \mathrm{M}$; Guangzhou RiboBio Co., Ltd.). Subsequently, cells were fixed with $4 \%$ formaldehyde for $20 \mathrm{~min}$ at room temperature, followed by the addition of $2 \mathrm{mg} / \mathrm{ml}$ of glycine for $5 \mathrm{~min}$ at room temperature. After treatment with $0.5 \%$ Triton X-100 at room temperature for $10 \mathrm{~min}$, the cells were washed twice with PBS and treated with $200 \mu \mathrm{l}$ of $1 \mathrm{X}$ Apollo reaction cocktail from a Cell-Light EdU Apollo488 In Vitro kit (Guangzhou RiboBio Co., Ltd.) for $20 \mathrm{~min}$ at room temperature, according to the manufacturer's protocol. The nuclear DNA was stained with DAPI $(5 \mu \mathrm{g} / \mathrm{ml})$ for $10 \mathrm{~min}$ at room temperature. Images were obtained using a fluorescence microscope (Motic Incorporation, Ltd.; magnification, x100).

Cell cycle assay. A-498 cells stably expressing shctrl or shRGS20 were seeded onto 6-well plates at a density of $3 \times 10^{5}$ cells/well. After $24 \mathrm{~h}$ of culture at $37^{\circ} \mathrm{C}$, the cells were harvested and fixed in $70 \%$ ethanol at $4^{\circ} \mathrm{C}$ overnight. After washing twice with PBS, the fixed cells were incubated in PBS containing $0.2 \%$ Triton $\mathrm{X}-100$ and $10 \mu \mathrm{g} / \mathrm{ml}$ RNase at $37^{\circ} \mathrm{C}$ for $30 \mathrm{~min}$. Subsequently, the cells were incubated with 
Table I. Primer sequences used to generate shRGS20 lentiviruses.

Name

Sequence $\left(5^{\prime}-3^{\prime}\right)$

shRGS20-1

Forward: CCGGGCTCGTGTCTCACTGTTAGAACTCGAGTTCTAACAGTGAGACACGAGCTTTTT Reverse: AATTAAAAAGCTCGTGTCTCACTGTTAGAACTCGAGTTCTAACAGTGAGACACGAGC

shRGS20-2 Forward: CCGGCCATCCCAACACATATTCGATCTCGAGATCGAATATGTGTTGGGATGGTTTTT

shctrl Reverse: AATTAAAAACCATCCCAACACATATTCGATCTCGAGATCGAATATGTGTTGGGATGG Forward: CCGGTTCTCCGAACGTGTCACGTCTCGAGACGTGACACGTTCGGAGAATTTTT Reverse: AATTAAAAATTCTCCGAACGTGTCACGTCTCGAGACGTGACACGTTCGGAGAA

sh, short hairpin; RGS20, regulator of G protein signaling 20; ctrl, control.

Table II. Primers used for quantitative PCR.

\begin{tabular}{ll}
\hline Name & \multicolumn{1}{c}{ Sequence (5'-3') } \\
\hline RGS20-F & CTTCCCACGAACTCAGAGCAGA \\
RGS20-R & TCCTTCCTGCTGGAGTGACCAT \\
CCNB1-F & GACCTGTGTCAGGCTTTCTCTG \\
CCNB1-R & GGTATTTTGGTCTGACTGCTTGC \\
CDC20-F & CGGAAGACCTGCCGTTACATTC \\
CDC20-R & CAGAGCTTGCACTCCACAGGTA \\
PTTG1-F & GCTTTGGGAACTGTCAACAGAGC \\
PTTG1-R & CTGGATAGGCATCATCTGAGGC \\
18S-F & CGACGACCCATTCGAACGTCT \\
$18 S-R$ & CTCTCCGGAATCGAACCCTGA
\end{tabular}

F, forward; R, reverse; RGS20, regulator of G protein signaling 20; CCNB1, cyclin B1; PTTG1, securin.

$20 \mu \mathrm{g} / \mathrm{ml}$ propidium iodide (PI; Invitrogen; Thermo Fisher Scientific, Inc.) at room temperature for $30 \mathrm{~min}$ in the dark and analyzed using the NovoCyte setup (ACEA Bioscience Inc.; Agilent Technologies, Inc.) and NovoExpress ${ }^{\circledR}$ software 1.4.1 (ACEA Bioscience Inc.; Agilent Technologies, Inc.).

Apoptosis assay. A total of $1 \times 10^{6} \mathrm{~A}-498$ cells stably expressing shctrl or shRGS20 were seeded onto 6-well plates. After $48 \mathrm{~h}$ of culture at $37^{\circ} \mathrm{C}$, adherent and floating cells were collected by centrifugation at $200 \mathrm{x} \mathrm{g}$ for $5 \mathrm{~min}$ at room temperature, washed with PBS and detected using an Annexin V-FITC/PI Apoptosis Detection kit (cat. no. A211-02; Vazyme Biotech Co., Ltd.) according to the manufacturer's protocol. The results were analyzed using the NovoCyte setup (ACEA Bioscience Inc.; Agilent Technologies, Inc.) and NovoExpress ${ }^{\circledR}$ software 1.4.1 (ACEA Bioscience Inc.; Agilent Technologies, Inc.). The results were presented as the percentage of apoptotic cells (including early and late apoptotic cells) relative to the total number of analyzed cells.

Wound healing assay. A-498 cells infected with shctrl or shRGS20 virus were seeded onto 6-well plates at $100 \%$ confluence. A straight-line wound was created by scratching the culture using a $2-\mu 1$ pipette tip. The cells were continuously cultured in medium without serum for $48 \mathrm{~h}$ at $37^{\circ} \mathrm{C}$ and observed using a light microscope (Motic Incorporation, Ltd.; magnification, $\mathrm{x} 40$ ). The percentage of the wound healing was quantified using Image J 1.8.0 software (National Institutes of Health).

Transwell assay. Migration was measured using Matrigel-free Transwell plates (Corning, Inc.) containing an $8-\mu \mathrm{m}$ porous membrane, while invasion was measured using Transwell plates precoated with $25 \%$ Matrigel at $37^{\circ} \mathrm{C}$ for $30 \mathrm{~min}$. In total, $1 \times 10^{5}$ A-498 cells stably expressing shRGS20 or shctrl were plated in the upper chambers of the Transwell plates in $100 \mu \mathrm{l}$ DMEM without FBS. A total of $500 \mu 1$ DMEM with $10 \%$ FBS was plated in the lower chambers of the Transwell plates. After $24 \mathrm{~h}$ of incubation $37^{\circ} \mathrm{C}$, migrating or invading cells were stained with $0.5 \%$ crystal violet at room temperature for $30 \mathrm{~min}$, and then the cells in six random fields were photographed and counted using a light microscope (Motic Incorporation, Ltd.; magnification, x100) and ImageJ v1.48 (National Institutes of Health), respectively.

Bioinformatics analysis. Clinical information and raw expression data from 539 patients with RCC were downloaded from The Cancer Genome Atlas (TCGA) database (https://portal. gdc.cancer.gov/). Among them, there were 340 patients with tumor stage 1 (T1) or T2, 190 patients with T3 or T4, 239 cases with no lymph node metastasis (N0), 16 cases with lymph node metastasis (N1), 420 cases with no distant metastasis (M0) and 78 cases with distant metastasis (M1).

RGS20 expression in tumor and adjacent normal tissues (ANTs) was compared using R Limma package (version 3.8) (24). Univariate and multivariate Cox proportional hazard regression, Kaplan-Meier survival analysis and receiver operating characteristic (ROC) curve analysis were performed. Gene set enrichment analysis (GSEA) was performed using GSEA version 2.0 to further understand the biological pathway of RGS20 in the pathogenesis of RCC, as previously described (25-27). Pearson's correlation analysis was used for ranking genes.

The interaction network among proteins expressed by RGS20-associated genes was established as previously described (24). The minimum interaction score required was 0.700 (high confidence), and the protein nodes that did not interact with other proteins were deleted. Subsequently, the Cytoscape software (http://www.cytoscape.org; version 3.7.1) was used to construct the interaction network, and the top 
10 hub genes were identified according to the Cytoscape plug-in (degrees ranking of cytoHubba). The co-expression gene network of RCC was analyzed as previously described (24). The cBioPortal database (http://www.cBioPortal.org/) was used to identify the RGS20 co-expressed genes. The genes with a Spearman correlation coefficient $>0.5$ or $<-0.5$ were selected to plot the gene co-expression network. Additionally, the associations between RGS20 expression and various immune cell infiltration in RCC were evaluated using CIBERSORT in $\mathrm{R}$ version 4.1.0, as previously described (28), and plotted using ggplot 2 in $\mathrm{R}$ version 4.1.0. The associations between RGS20 expression and various immune cell markers in RCC were assessed using the cBioPortal database (http://www. cBioPortal.org/), and plotted using ggplot 2 in $\mathrm{R}$ version 4.1.0.

Statistical analysis. All assays were performed independently at least three times. Data were presented as the mean \pm SD. All statistical analyses were performed using SPSS software 22.0 (IBM Corp.), and GraphPad Prism 8.2.1 (GraphPad Software, Inc.) was used to plot the graphs. Mann-Whitney test was performed for non-parametric data between two groups. Wilcoxon signed rank test was used to compare matched samples for non-parametric data. One-way ANOVA followed by Tukey's post-hoc test was used to identify the significant differences among multiple groups. $\mathrm{P}<0.05$ was considered to indicate a statistically significant difference.

\section{Results}

RGS20 mRNA expression is increased in RCC tissues and cell lines. The high-throughput RNA sequencing data of the TCGA RCC cohort was analyzed, revealing that RGS20 mRNA expression was significantly increased in tumor tissues compared with in ANTs (Fig. 1A and B).

In addition, the association between RGS20 mRNA expression and the TNM stage, tumor (T) stage, lymph node metastasis or distant metastasis was analyzed. It was revealed that RGS20 mRNA expression was significantly higher in RCC tissues at stage III + IV than at stage I + II, as well as at T stage $3+4$ than at T stage $1+2$ (Fig. 1C and D). Additionally, RGS20 mRNA expression in metastatic RCC (N1, M1) was significantly higher than in non-metastatic RCC (N0, M0) (Fig. 1E and F). These data suggested that RGS20 may be involved in RCC progression.

This observation was validated by comparing RGS20 expression between RCC cell lines (786-O, A-498, SN12-PM6 and Caki-1) and the normal renal tubular epithelial cell line, HK-2, using qPCR and western blot analysis. As shown in Fig. $1 \mathrm{G}$ and $\mathrm{H}$, both the mRNA and protein expression levels of RGS20 were significantly higher in RCC cell lines than in HK-2 cells. RGS20 expression was the highest in A-498 cells; thus, A-498 cells were chosen for subsequent experiments.

In summary, the present results indicated that RGS20 mRNA, which was highly expressed in RCC tissues, may be closely associated with the progression and metastasis of RCC. Moreover, the mRNA and protein expression levels of RGS20 were high in RCC cell lines.

Patients with RCC with high RGS20 mRNA expression have a poorer survival rate than those with low RGS20 mRNA expression. Next, the clinical outcome of patients with RCC from TCGA database having low or high RGS20 mRNA expression was investigated using Kaplan-Meier survival analysis. The patients were divided into two groups, high and low level, based on the median RGS20 mRNA expression value (median value, 16.17291467). The survival rate of patients with RCC with high RGS20 mRNA expression was significantly worse than that of patients with low RGS20 mRNA expression $(\mathrm{P}<0.0001$; Fig. 2A). Among female patients, male patients, patients aged $>65$ years, patients aged $\leq 65$ years, patients with stage III and IV, T stage 1 and 2, T stage 3 and 4, M0 or M1, those with high RGS20 mRNA expression had a significantly worse survival rate than those with low RGS20 mRNA expression (Fig. 2B-F). These results indicated that the upregulation of RGS20 mRNA expression in RCC tissues is associated with a poor prognosis in these patients.

In addition, the ROC curve analysis revealed that RGS20 expression could not effectively distinguish patients at different stages, including living/dead stage (Fig. S1A), grade $1+$ grade $2 /$ grade $3+\operatorname{grade} 4$ (Fig. S1B), stage I + stage II/stage III + stage IV (Fig. S1C), T stage $1+\mathrm{T}$ stage $2 /$ T stage $3+$ T stage 4 (Fig. S1D), and N0/N1 (Fig. S1E). However, the expression levels of RGS20 may be used to distinguish M0 and M1 stage patients (Fig. S1F, one year: $\mathrm{AUC}=0.769,95 \% \mathrm{CI}$ : 0.694-0.844; five years: $\mathrm{AUC}=0.718$, 95\% CI: 0.634-0.803). Moreover, univariate and multivariate Cox proportional hazard regression analyses were performed. In the univariate analysis, age, T stage, TNM stage, distant metastasis and RGS20 expression were significantly associated with overall survival (OS) in RCC (all $\mathrm{P}<0.05$; Table III). The subsequent multivariate analysis confirmed that RGS20 upregulation (HR, 1.193; 95\% CI, 1.092-1.304; $\mathrm{P}<0.001$ ), age (HR, 1.6966; 95\% CI, 1.235-2.330; $\mathrm{P}=0.001)$ and TNM stage (HR, 1.660; 95\% CI, 1.081-2.549; $\mathrm{P}=0.021$ ) were independent indicator of unfavorable OS in RCC after adjusting other prognostic indicators (Table III). In summary, these findings suggested that the prognosis of patients with RCC with high RGS20 mRNA expression was poorer than that of patients with low RGS20 expression.

RGS20 enhances cell proliferation and suppresses apoptosis. To study the function of RGS20 in RCC, a lentivirus system was used to knock down its expression in A-498 cells. Two lentiviruses targeting human RGS20 (shRGS20-1 and shRGS20-2) and a negative control (shctrl) were generated and used to construct A-498 stably transfected cell lines. The silencing effect was then assessed using western blot analysis and qPCR. The results indicated that shRGS20-1 and shRGS20-2 effectively inhibited the expression levels of endogenous RGS20 in A-498 cells (Fig. 3A and B).

An MTT assay was used to study the effect of RGS20 on cell proliferation. The proliferation of A-498 cells stably expressing shRGS20 was significantly lower than that of A-498 cells stably expressing shctrl, indicating that RGS20 promoted cell proliferation (Fig. 3C). Moreover, the EdU proliferation assay revealed that the RGS20-knockdown cells had a significantly lower EdU ${ }^{+}$rate compared with control cells, suggesting that RGS20 increased the percentage of EdU ${ }^{+}$cells (Fig. 3D and E). In addition, the cell cycle assay results indicated that RGS20-knockdown increased the percentage of cells in the 
A

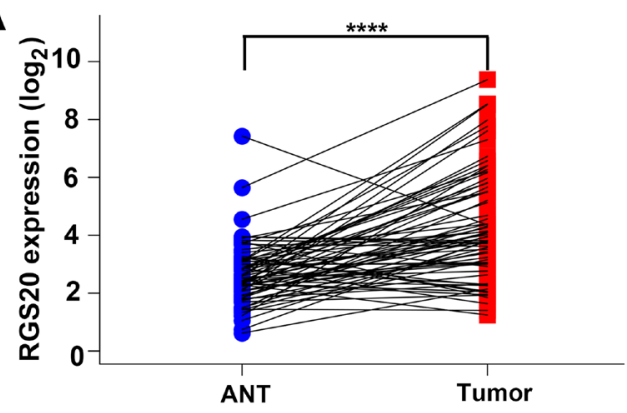

C

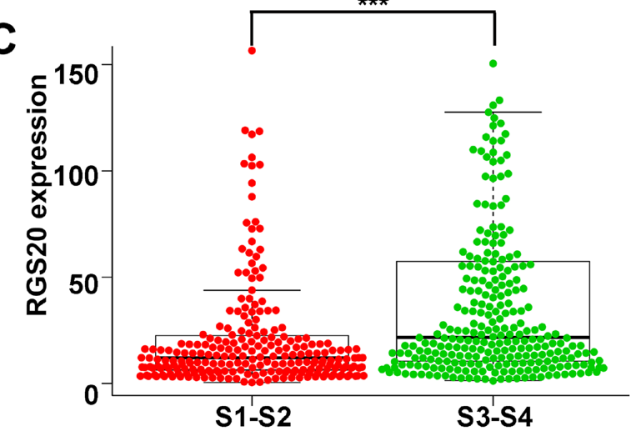

E

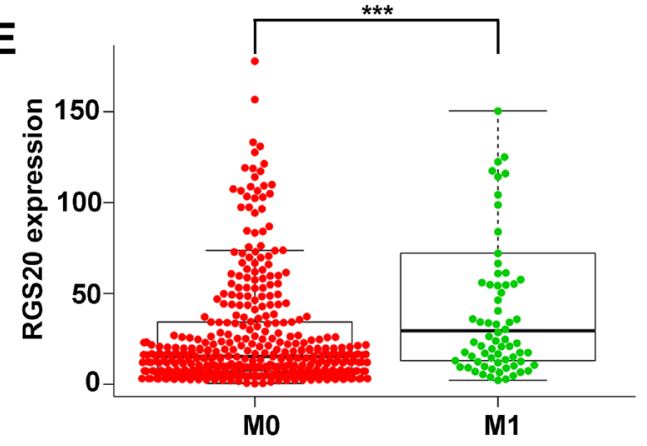

B

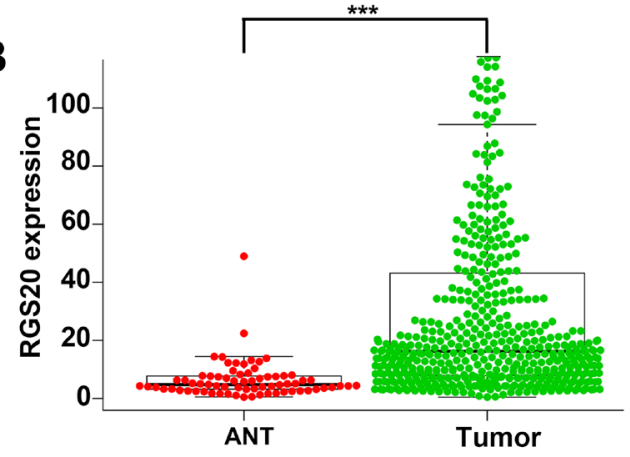

D

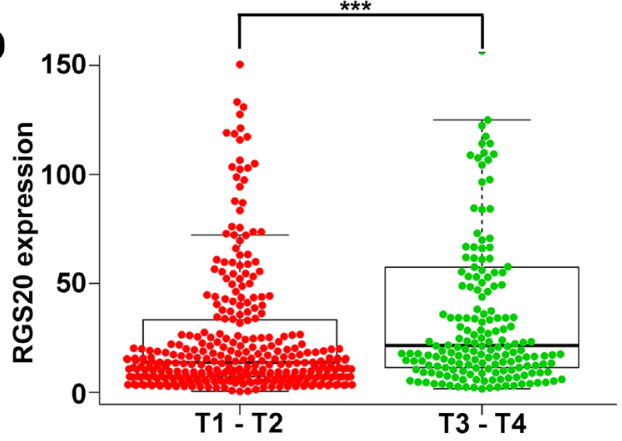

F

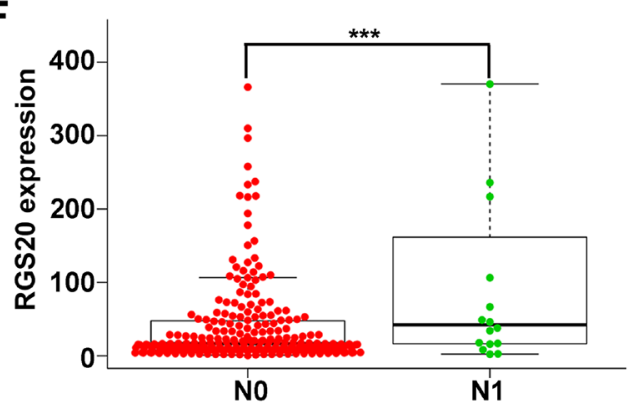

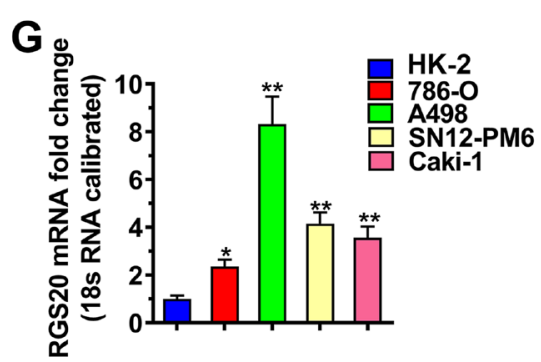
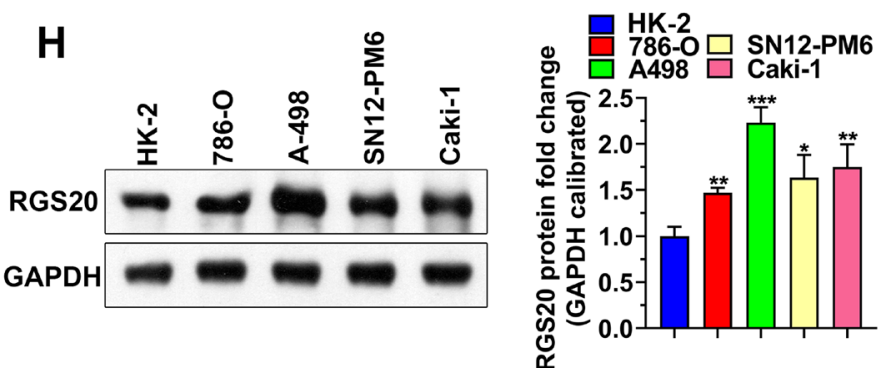

Figure 1. RGS20 expression is upregulated in RCC tissues. (A) RGS20 expression was significantly increased in RCC tissues compared with in paired ANTs of patients from TCGA RCC dataset. (B) Comparison between the RGS20 mRNA expression in ANTs and unpaired RCC tissues from TCGA. Association between RGS20 expression and (C) TNM stage, (D) T stage, (E) M stage and (F) N stage in RCC. ${ }^{* * *} \mathrm{P}<0.001$ and ${ }^{* * * *} \mathrm{P}<0.0001$. RGS20 expression in five cell lines (HK-2, 786-O, A-498, SN12-PM6 and Caki-1) was analyzed using $(\mathrm{G})$ quantitative PCR and $(\mathrm{H})$ western blot analysis. Data are representative of $\geq 3$ independent experiments and shown as mean $\pm \mathrm{SD} .{ }^{*} \mathrm{P}<0.05,{ }^{* *} \mathrm{P}<0.01$ and ${ }^{* * *} \mathrm{P}<0.001$ vs. HK-2. ANTs, adjacent normal tissues; $\mathrm{S}, \mathrm{TNM}$ stage; T, tumor; M, distant metastasis; N, lymph node metastasis; RGS20, regulator of G protein signaling 20; TCGA, The Cancer Genome Atlas; RCC, renal cell carcinoma.

$\mathrm{G}_{0} / \mathrm{G}_{1}$ phase, which suggested that RGS20 promoted cell proliferation (Fig. 3F and G). An Annexin V/PI staining assay using flow cytometry revealed that RGS20-knockdown significantly increased the proportion of apoptotic cells (Fig. 3H and I). These results indicated that RGS20 normally inhibited apoptosis.

RGS20 promotes the migration and invasion of RCC cells. A wound healing assay demonstrated that compared with the shctrl group, the wound area of the shRGS20-1 group and the shRGS20-2 group was significantly larger, indicating that the wound healing capacity of A-498 cells was decreased with the knockdown of RGS20 (Fig. 4A). Moreover, a Transwell migration assay was used to evaluate the effect of RGS20 on cell migration. The data revealed that the knockdown of RGS20 significantly decreased the number of migrated cells, indicating that RGS20 promoted cell migration (Fig. 4B and C). Consistent with these findings, the Matrigel invasion assay revealed that RGS20-knockdown also significantly decreased the number of 

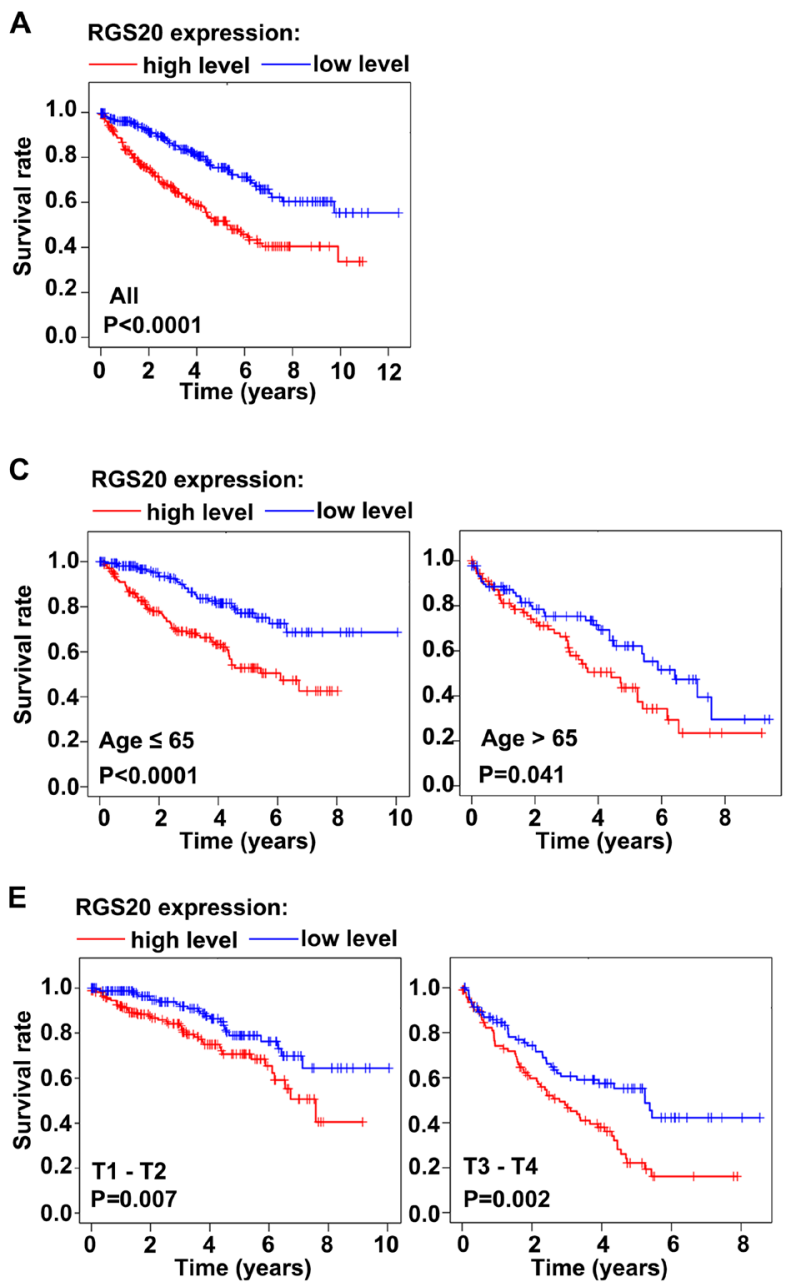

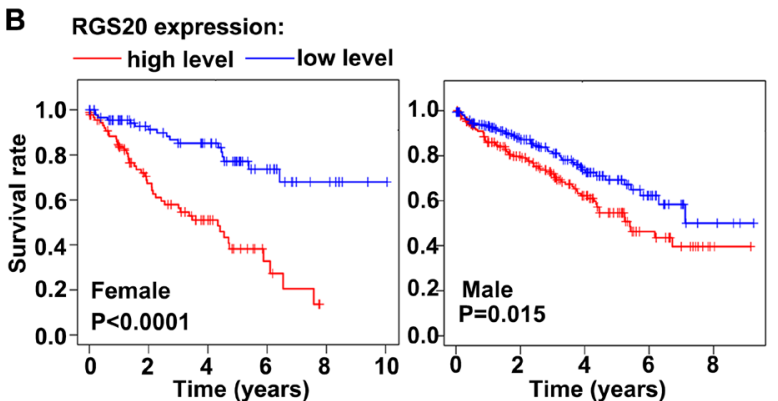

D RGS20 expression:

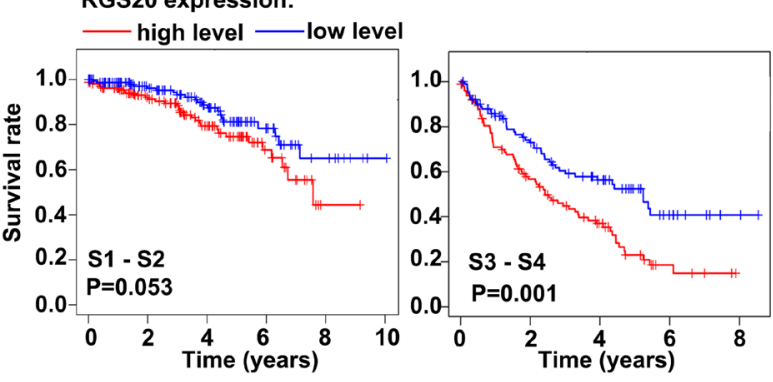

F RGS20 expression:

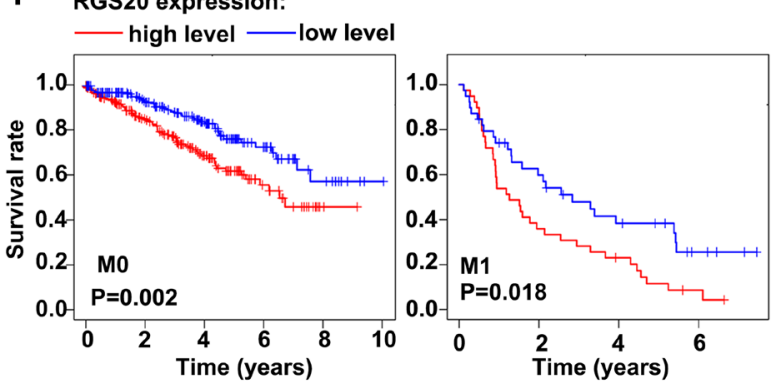

Figure 2. Patients with RCC with high RGS20 mRNA expression have a poor survival. (A) Kaplan-Meier survival analysis was used to evaluate the association between RGS20 mRNA expression and the overall survival rate in patients with RCC. Kaplan-Meier survival analysis was performed in subgroups, including (B) sex, (C) age, (D) TNM stage, (E) T stage and (F) M stage. RGS20, regulator of G protein signaling 20; S, TNM stage; T, tumor; M, distant metastasis; RCC, renal cell carcinoma.

invasive cells, indicating that RGS20 normally promoted cell invasion (Fig. 4D and E).

$R G S 20$ regulates the expression levels of securin (PTTG1), $C D C 20$ and cyclin B1 (CCNB1) in RCC cells. A previous study has demonstrated that RGS20 regulates cell cycle-associated indicators in OSCC cells (17). Therefore, GSEA analysis was conducted in the present study to investigate the effect of RGS20 mRNA expression on cell cycle pathways in RCC. The data revealed that there was significant correlation between RGS20 expression and the cell cycle (Fig. 5A). The three genes with the highest rank metric scores were PTTG1, CDC20 and CCNB1 (Fig. 5B). This observation was further evaluated using qPCR. As shown in Fig. 5C, the knockdown of RGS20 significantly decreased the mRNA expression levels of PTTG1, CDC20 and CCNB1.

Protein-protein interaction (PPI) network and gene co-expression network. The cBioPortal database was used to identify the RGS20 co-expressed genes, and a total of 72 genes with Spearman correlation coefficients $<-0.5$ or $>0.5$ were selected for gene co-expression network, which showed that RGS20 was positively correlated with inhibitor of nuclear factor- $\kappa \mathrm{B}$ kinase subunit $\varepsilon$ (IKBKE) (Fig. 6A). Subsequently, genes with Spearman correlation coefficients $<-0.3$ or $>0.3$ were selected for the protein interaction networks. A total of 54 genes were filtered into the target gene PPI network, and 10 hub genes (LPAR2, CAPZA1, AURKB, ARPC3, AGTR1, SAA1, PSMA2, PYCARD, ANXA2 and GLA) were screened using Cytoscape 3.7.1 (Fig. 6B). The available data was not sufficient to demonstrate that RGS20 interacts with these proteins; thus, further investigation is required.

Correlations between RGS20 expression andimmune infiltration in $R C C$. It has been previously shown that immune cells in the tumor microenvironment can affect tumor progression (29). Moreover, the aforementioned findings suggested the promoting role of RGS20 in RCC. Therefore, whether RGS20 expression was associated with immune infiltration was further investigated. The results revealed that RGS20 expression was associated with the infiltration level of activated CD4 T cells, type $1 \mathrm{~T}$ helper cells and activated dendritic cells (Fig. 7A).

In order to further understand the potential association between RGS20 and infiltrating immune cells, the association between RGS20 and several immune cell markers was studied, revealing that RGS20 expression was associated to a 
Table III. Univariate and multivariate Cox regression analyses for overall survival in patients with renal cell carcinoma.

Univariate analysis

Factors

RGS20 expression (low vs. high)

Age ( $\leq 65$ vs. $>65$ years)

Sex (male vs. female)

Stage (I+II vs. III+IV)

T stage (T1+T2 vs. T3+T4)

M stage (M0 vs. M1)

Hazard ratio $(95 \%$ CI)

$1.319(1.214-1.432)$

$1.659(1.216-2.263)$

$0.931(0.675-1.284)$

1.889 (1.649-2.164)

$1.941(1.639-2.299)$

4.284 (3.106-5.908)
Multivariate analysis

P-value

Hazard ratio $(95 \% \mathrm{CI})$

P-value

$<0.001$

0.001

0.663

$<0.001$

$<0.001$

$<0.001$

$1.193(1.092-1.304)$

$1.6966(1.235-2.330)$

$0.892(0.643-1.238)$

1.660 (1.081-2.549)

$0.878(0.593-1.298)$

$1.275(0.663-2.453)$
$<0.001$

0.001

0.494

0.021

0.513

0.467

RGS20, regulator of $\mathrm{G}$ protein signaling 20; T, tumor; $\mathrm{M}$, distant metastasis.

A

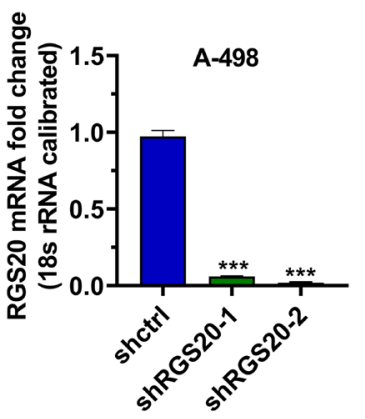

D

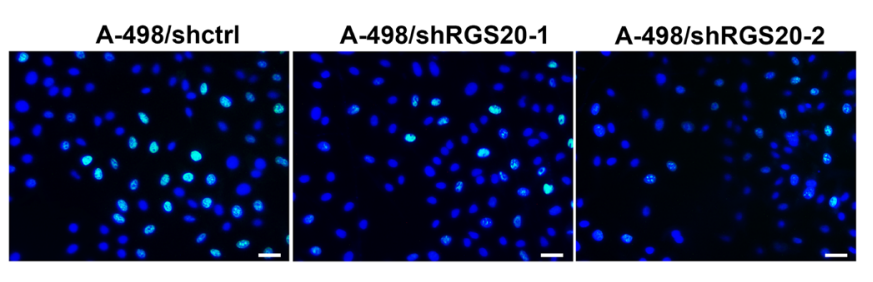

F
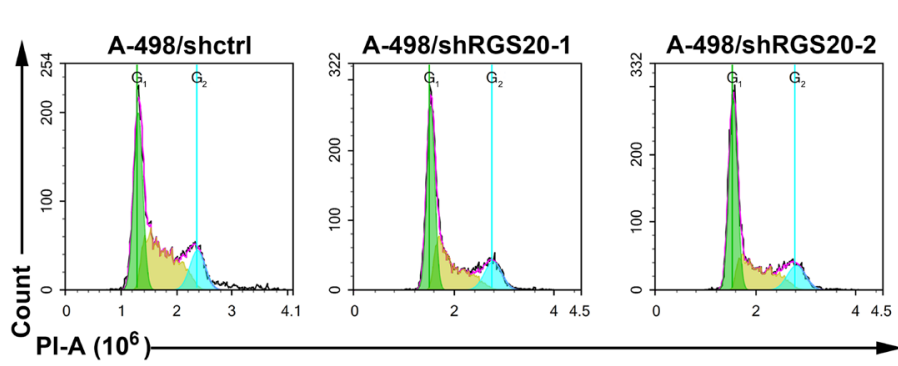

H

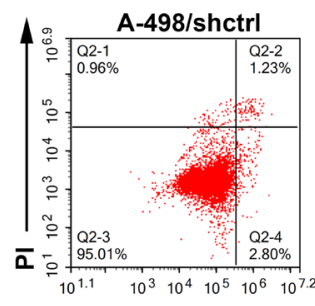

Annexin $\mathrm{V}$

B
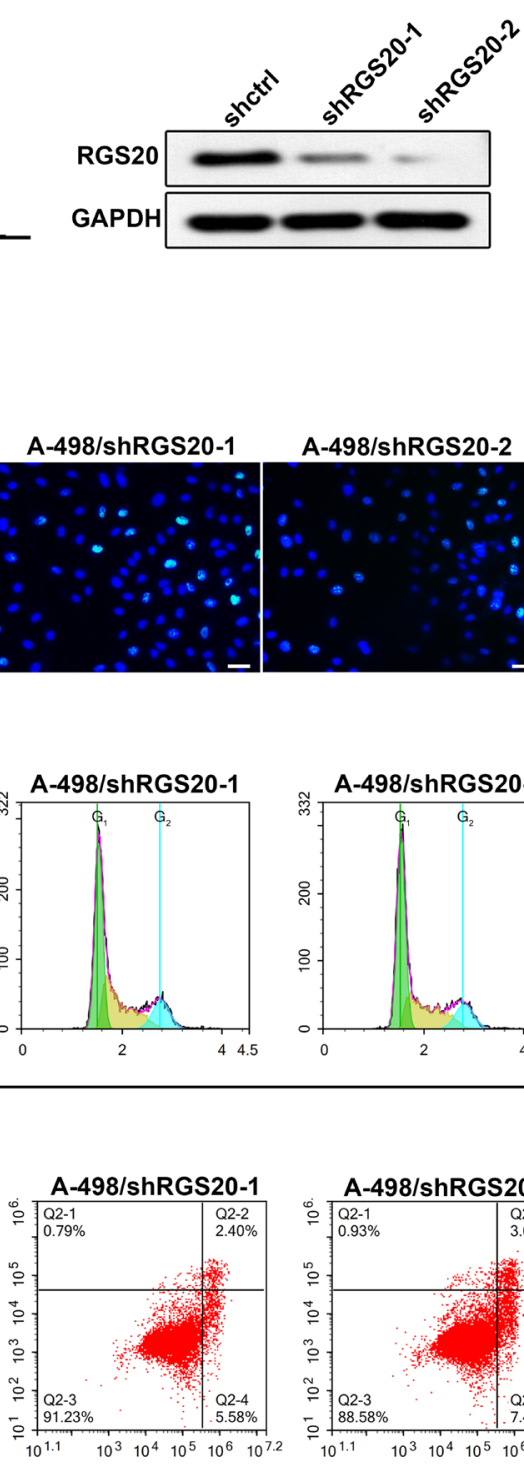

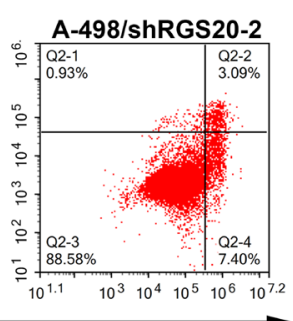

E

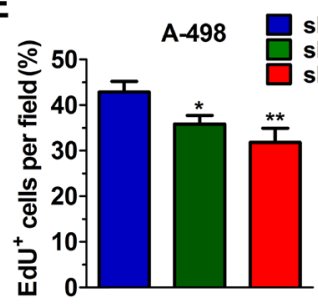

G

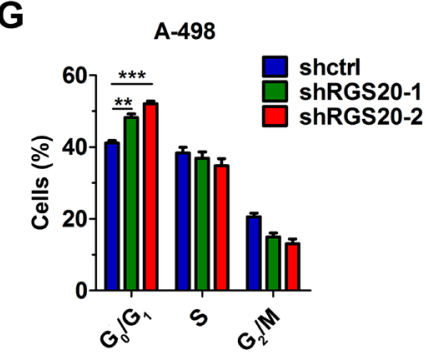

I

C
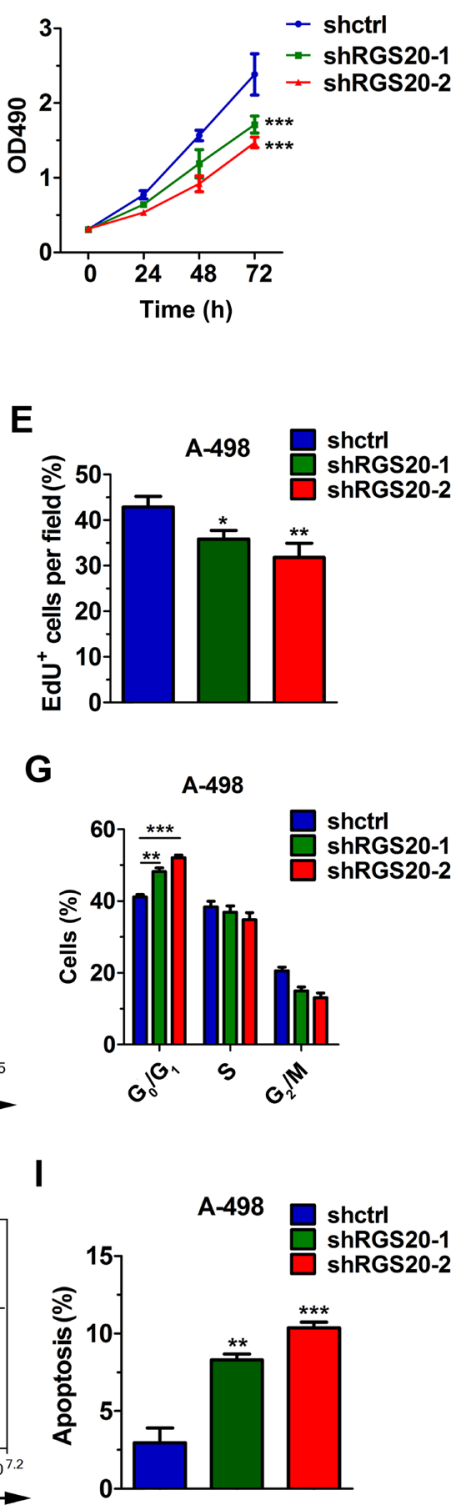

Figure 3. RGS20 enhances cell proliferation and suppresses apoptosis. The silencing effect of shRGS20 was evaluated using (A) quantitative PCR and (B) western blot analysis in A-498 cells. (C) Results of the MTT assay performed in control cells and RGS20-knockdown cells. (D) Representative images of the EdU proliferation assay. Scale bar, $50 \mu \mathrm{m}$. (E) Quantification of EdU ${ }^{+}$cells $(\mathrm{n}=3)$. (F) Representative images of cell cycle analysis. (G) RGS20-knockdown induced $\mathrm{G}_{0} / \mathrm{G}_{1}$ arrest. (H) Representative images of apoptosis analysis. (I) RGS20 inhibited the apoptosis of renal cell carcinoma cells. The results are presented as the mean \pm SD of triplicate wells. ${ }^{*} \mathrm{P}<0.05,{ }^{* *} \mathrm{P}<0.01$ and ${ }^{* * *} \mathrm{P}<0.001$ vs. shctrl. sh, short hairpin; ctrl, control; RGS20, regulator of $\mathrm{G}$ protein signaling 20; OD, optical density. 


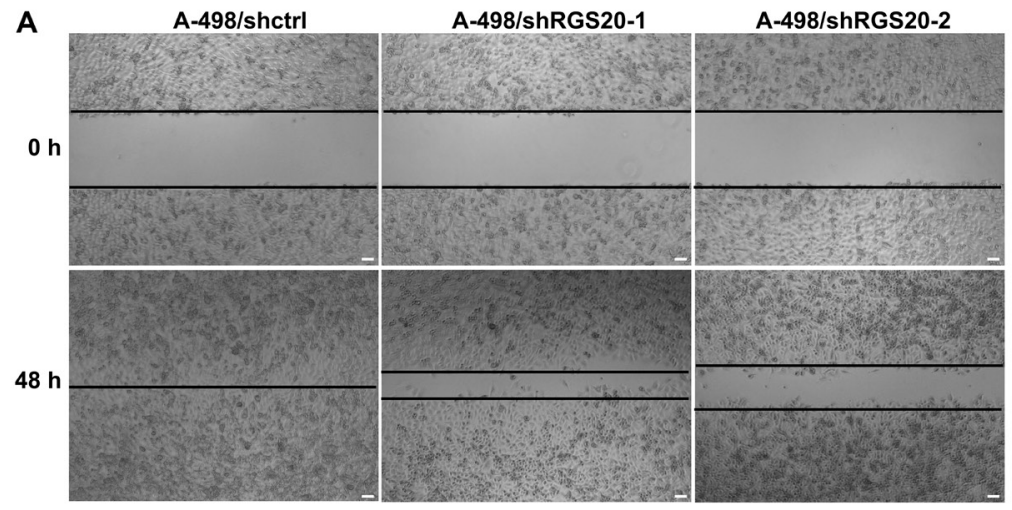

B

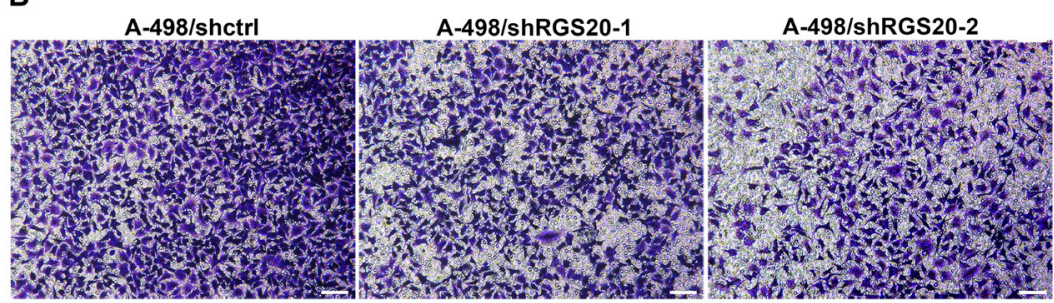

D

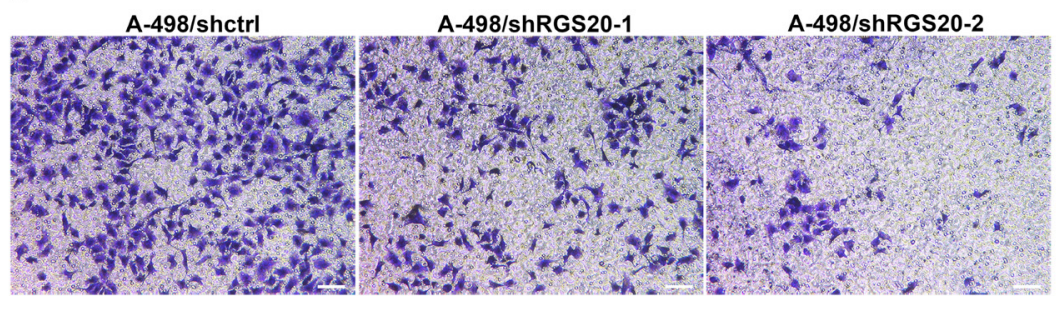

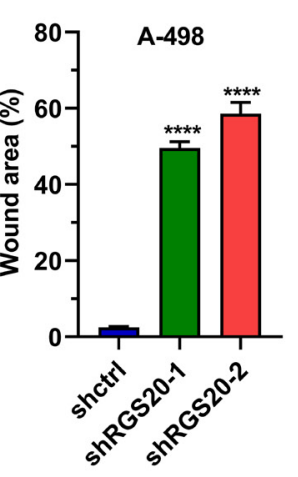

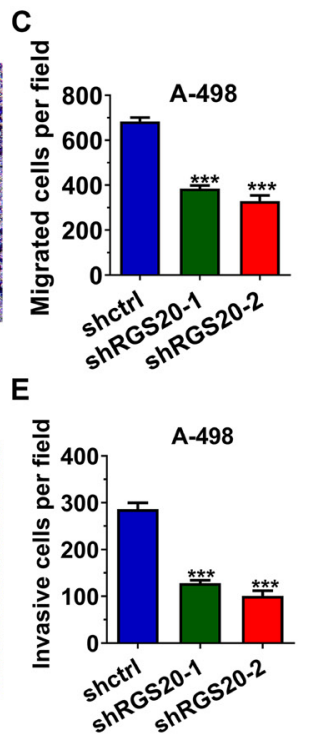

Figure 4. RGS20 promotes the migration and invasion of renal cell carcinoma cells. (A) Knockdown of RGS20 inhibited cell migration in A-498 cells, as tested using wound healing assay. Scale bar, $200 \mu \mathrm{m}$. Transwell assays revealed that shRNA-mediated RGS20-knockdown abrogated the (B and C) migration and (D and E) invasion of A-498 cells. Scale bar, $100 \mu \mathrm{m}$. The data are represented as the mean \pm SD of triplicate wells. ${ }^{* * *} \mathrm{P}<0.001$ and ${ }^{* * * * *} \mathrm{P}<0.0001$ vs. shctrl. sh, short hairpin; ctrl, control; RGS20, regulator of G protein signaling 20.

A

\section{Enrichment profile \\ - Hits \\ - Ranking metric scores}

Enrichment plot: Cell cycle

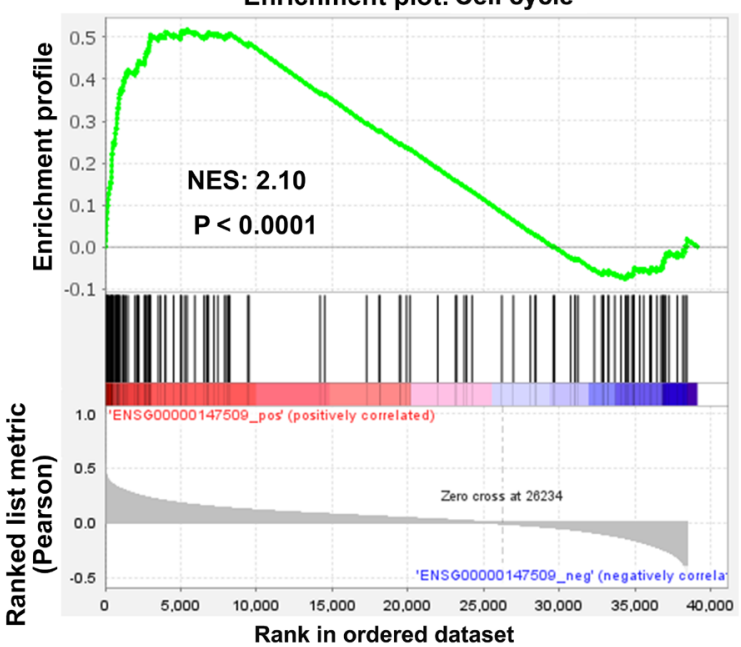

B

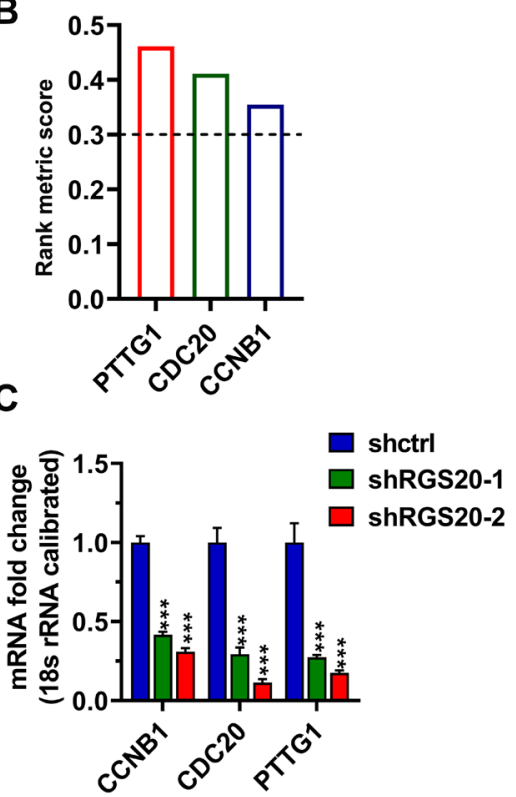

Figure 5. Knockdown of RGS20 regulates the mRNA expression levels of PTTG1, CDC20 and CCNB1 in renal cell carcinoma cell lines. (A and B) Gene set enrichment analysis identified PTTG1, CDC20 and CCNB1 as regulatory targets of RGS20. (C) mRNA expression levels of the indicated genes in the RGS20-knokdown A-498 cells were analyzed using quantitative PCR. Data are representative of $\geq 3$ independent experiments and are shown as mean \pm SD. ${ }^{* * * *} \mathrm{P}<0.001$ vs. shctrl. sh, short hairpin; ctrl, control; RGS20, regulator of G protein signaling 20; CCNB1, cyclin B1; PTTG1, securin; NES, normalized enrichment score. 

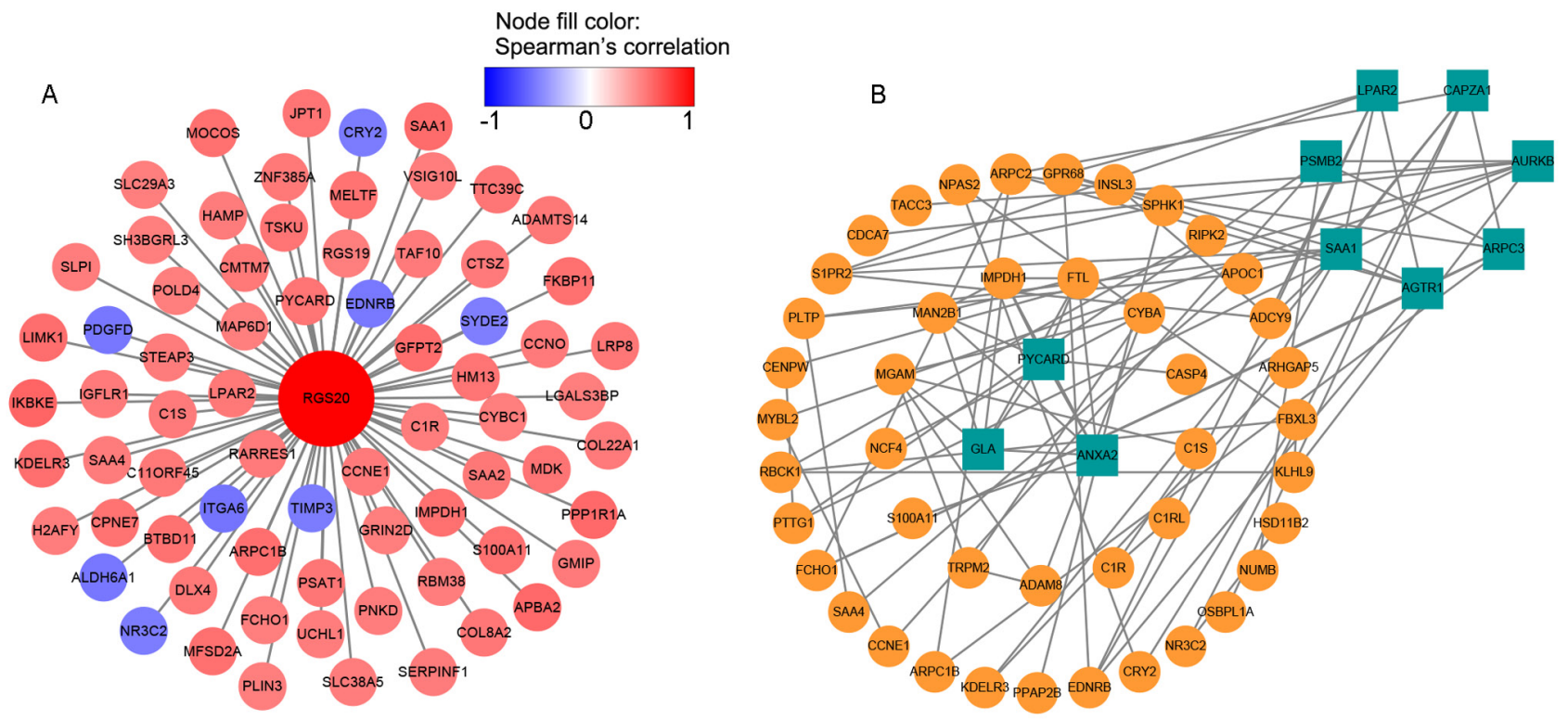

Figure 6. PPI network and gene co-expression network. (A) Construction of gene co-expression networks. The blue color represents genes that are negatively correlated with RGS20, and the light red color indicates genes that are positively correlated with RGS20. (B) PPI network. The green color represents the hub genes, and the orange color indicates the other genes of the PPI network. RGS20, regulator of G protein signaling 20; PPI, protein-protein interaction.

A

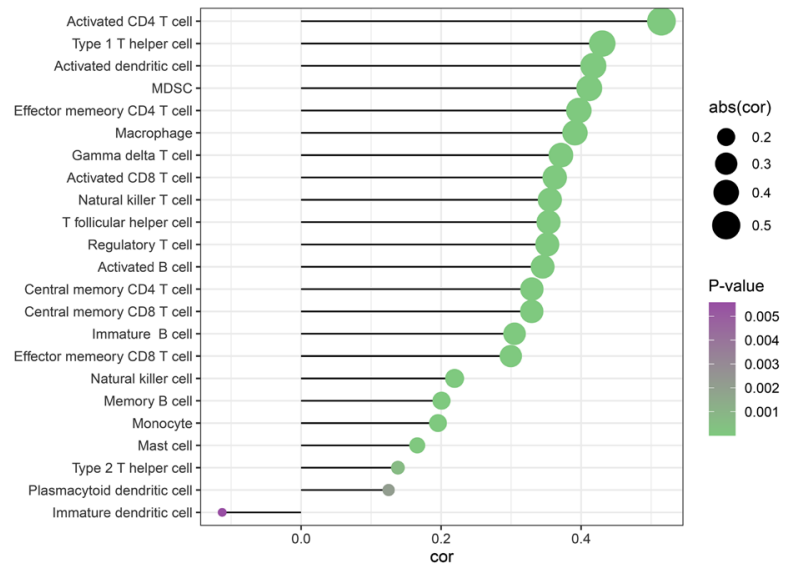

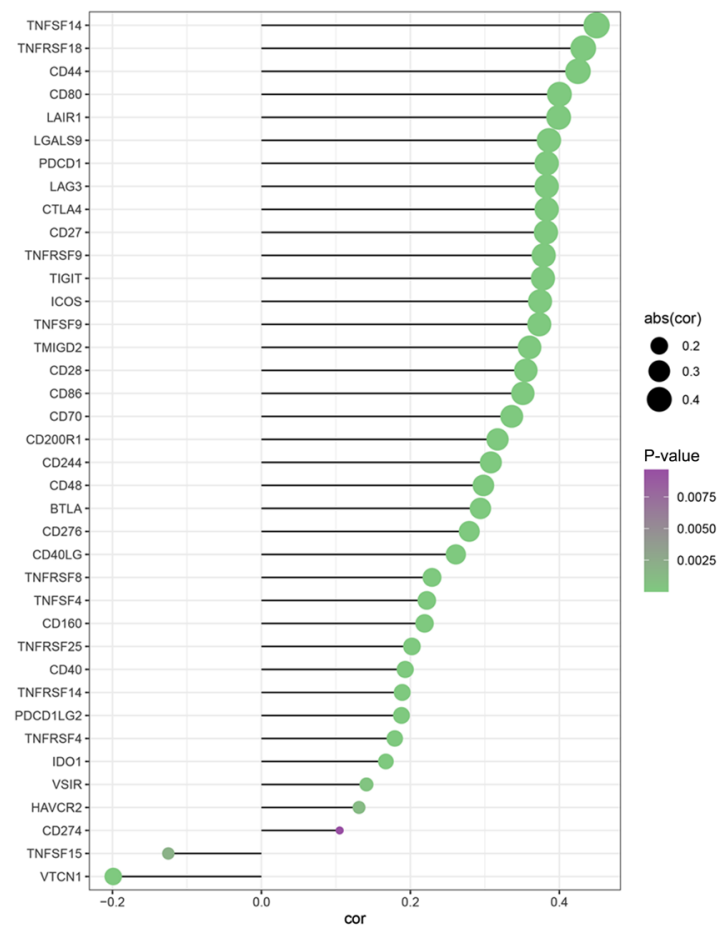

Figure 7. Association of RGS20 expression with immune infiltration in renal cell carcinoma. (A) Association of RGS20 expression with infiltrating immune cells. (B) Association of RGS20 expression with immune markers. RGS20, regulator of G protein signaling 20; abs, absolute value; cor, correlation index.

number of immune cell markers in RCC, including TNFSF14, TNFRSF18 and CD44 (Fig. 7B). Overall, RGS20 may have the potential to promote immune infiltration in RCC.

\section{Discussion}

It has been demonstrated that most RGS proteins are involved in the occurrence and development of various types of cancer, including breast, ovarian, lung and prostate cancer (19,30-33); therefore, targeting these proteins has great therapeutic potential. The present study revealed that elevated RGS20 mRNA expression was associated with a poor prognosis in patients with RCC and that the knockdown of RGS20 inhibited the motility of RCC cell lines. These data indicated the importance of RGS20 in the diagnosis and treatment of RCC. A previous study has reported that RGS20 expression is upregulated in various types of tumor, such as triple-negative breast cancer and lung cancer (19). In the present study, TCGA database was 
analyzed to demonstrate that RGS20 mRNA expression in RCC tissues was higher than that in ANTs. Kaplan-Meier survival analysis revealed that high mRNA expression levels of RGS20 were associated with a decreased survival rate of patients. This indicated that RGS20 may be a potential biomarker for the diagnosis and prognosis estimation of patients with RCC.

A study has indicated that RGS20 can enhance the aggregation, migration, invasion and adhesion of H1299, A549, HeLa and MDA-MB-231 cell lines (21). Consistent with these findings, knocking out RGS20 in RCC cell lines in the present study severely impaired cell migration and invasion. In addition, the knockdown of RGS20 induced $\mathrm{G}_{1}$ arrest and apoptosis in A-498 cells, which may contribute to cell proliferation inhibition. Another study has identified that RGS20 is lowly expressed in luminal breast cancer tissues and highly expressed in triple-negative breast cancer (TNBC) tissues by analyzing the data from TCGA, indicating that the expression patterns of RGS20 are different in different types of tumor (19). Moreover, data from TCGA indicated that RGS20 expression in TNBC with lymph node metastasis was higher than that in TNBC without lymph node metastasis, and immunohistochemistry revealed that TNBC tissues with high RGS20 expression had a risk of lymph node metastasis (19). Consistent with the aforementioned studies, the present study revealed that RGS20 mRNA expression in RCC tissues with lymph node metastasis and distant metastasis was higher than that in RCC tissues without metastasis, suggesting that RGS20 may promote RCC metastasis.

To elucidate the possible mechanism of RGS20-mediated motility of RCC cells, GSEA was performed to identify the associated biological processes and signaling pathways using high throughput RNA sequencing data of TCGA RCC cohort. The results revealed that the cell cycle-associated genes PTTG1, CDC20 and CCNB1 were associated with RGS20 expression. CDC20 acts as a regulatory protein at multiple points in the cell cycle and is involved in late nuclear movement and chromosome segregation (34). CCNB1 is a regulatory protein involved in mitosis and controls the $\mathrm{G}_{2} / \mathrm{M}$ transition phase of the cell cycle (35). PTTG1, which is highly expressed in various types of tumor, including breast, ovarian and head and neck cancer, promotes sister chromatid separation, in vitro transformation and in vivo tumorigenic activities (36). The present study demonstrated that following the knockdown of RGS20, the mRNA expression levels of PTTG1, CDC20 and CCNB1 in RCC cells were significantly decreased, suggesting that RGS20 may affect cell proliferation, migration and invasion by regulating the expression levels of those three genes.

Gene co-expression network analysis demonstrated that RGS20 was highly positively correlated with IKBKE (Fig. 6A). Studies have confirmed that IKBKE promotes the development of pancreatic cancer, non-small cell lung cancer, epithelial squamous cell carcinoma and other types of cancer (37-39). Therefore, the present study speculated that RGS20 may play a synergistic role with IKBKE in promoting tumor growth.

Overall, the current results highlight the role of RGS20 in tumorigenesis and metastasis. However, the present study has some limitations, including the lack of immunohistochemical and qPCR detection of RCC tissues, as well as related animal experiments. Another limitation of the study was that ROC curve analysis indicated that RGS20 expression could not be used to predict patient status, grade, TNM stage and T stage of tumor.

In summary, the present study demonstrated that RGS20 may serve a vital role in the proliferation and metastasis of RCC cells, opening new avenues for targeted therapy of RCC. Furthermore, these biological processes may be regulated by RGS20 via regulating the expression levels of PTTG1, CDC20 and CCNB1. Since high RGS20 expression was associated with a poor prognosis in patients with RCC, inhibiting RGS20 expression in tumor tissues may constitute an effective treatment strategy.

\section{Acknowledgements}

Not applicable.

\section{Funding}

The present study was supported by the Academic research project of academician expert workstation of Xiamen Fifth Hospital (grant no. 2018YJ005).

\section{Availability of data and materials}

The datasets used and/or analyzed during the current study are available from the corresponding author on reasonable request.

\section{Authors' contributions}

LJ, YH and ZW designed and coordinated the study. LJ, JS and NZ performed the experiments, and acquired and analyzed data. LJ, JS, NZ, YH and ZW interpreted the data. LJ, YH and $\mathrm{ZW}$ wrote the manuscript. $\mathrm{YH}$ and $\mathrm{ZW}$ were responsible for confirming the authenticity of all the raw data. All authors read and approved the final version of the manuscript.

\section{Ethics approval and consent to participate}

Not applicable.

\section{Patient consent for publication}

Not applicable.

\section{Competing interests}

The authors declare that they have no competing interests.

\section{References}

1. Khalil Ibrahim A: Trends of adult primary malignant renal tumors over 6 years. Pak J Med Sci 29: 1385-1388, 2013.

2. Zhai W, Zhu R, Ma J, Gong D, Zhang H, Zhang J, Chen Y, Huang Y, Zheng J and Xue W: A positive feed-forward loop between LncRNA-URRCC and EGFL7/P-AKT/FOXO3 signaling promotes proliferation and metastasis of clear cell renal cell carcinoma. Mol Cancer 18: 81, 2019.

3. Ferlay J, Soerjomataram I, Dikshit R, Eser S, Mathers C, Rebelo M, Parkin DM, Forman D and Bray F: Cancer incidence and mortality worldwide: Sources, methods and major patterns in GLOBOCAN 2012. Int J Cancer 136: E359-E386, 2015.

4. Chen W, Sun K, Zheng R, Zeng H, Zhang S, Xia C, Yang Z, Li H, Zou X and He J: Cancer incidence and mortality in China, 2014. Chin J Cancer Res 30: 1-12, 2018. 
5. Wong MCS, Goggins WB, Yip BHK, Fung FDH, Leung C, Fang Y, Wong SYS and Ng CF: Incidence and mortality of kidney cancer: Temporal patterns and global trends in 39 countries. Sci Rep 7: 15698, 2017.

6. Siegel RL, Miller KD and Jemal A: Cancer statistics, 2018. CA Cancer J Clin 68: 7-30, 2018.

7. Ravaud A, Motzer RJ, Pandha HS, George DJ, Pantuck AJ, Patel A, Chang YH, Escudier B, Donskov F, Magheli A, et al: Adjuvant sunitinib in high-risk renal-cell carcinoma after nephrectomy. N Engl J Med 375: 2246-2254, 2016.

8. Frank I, Blute ML, Cheville JC, Lohse CM, Weaver AL, Leibovich $\mathrm{BC}$ and Zincke $\mathrm{H}$ : A multifactorial postoperative surveillance model for patients with surgically treated clear cell renal cell carcinoma. J Urol 170: 2225-2232, 2003

9. Patard JJ, Kim HL, Lam JS, Dorey FJ, Pantuck AJ, Zisman A, Ficarra V, Han KR, Cindolo L, De La Taille A, et al: Use of the University of California Los Angeles integrated staging system to predict survival in renal cell carcinoma: An international multicenter study. J Clin Oncol 22: 3316-3322, 2004.

10. Sorbellini M, Kattan MW, Snyder ME, Reuter V, Motzer R, Goetzl M, McKiernan J and Russo P: A postoperative prognostic nomogram predicting recurrence for patients with conventional clear cell renal cell carcinoma. J Urol 173: 48-51, 2005.

11. Calvo E, Schmidinger M, Heng DY, Grünwald V and Escudier B Improvement in survival end points of patients with metastatic renal cell carcinoma through sequential targeted therapy. Cancer Treat Rev 50: 109-117, 2016.

12. Chen Z, Zhu R, Zheng J, Chen C, Huang C, Ma J, Xu C, Zhai W and Zheng J: Cryptotanshinone inhibits proliferation yet induces apoptosis by suppressing STAT3 signals in renal cell carcinoma. Oncotarget 8: 50023-50033, 2017.

13. Wang Y,Ho G, Zhang JJ, Nieuwenhuijsen B, Edris W, Chanda PK and Young KH: Regulator of G protein signaling Z1 (RGSZ1) interacts with Galpha i subunits and regulates Galpha i-mediated cell signaling. J Biol Chem 277: 48325-48332, 2002.

14. De Vries L, Elenko E, Hubler L, Jones TL and Farquhar MG: GAIP is membrane-anchored by palmitoylation and interacts with the activated (GTP-bound) form of G alpha i subunits. Proc Natl Acad Sci USA 93: 15203-15208, 1996.

15. Nunn C, Mao H, Chidiac P and Albert PR: RGS17/RGSZ2 and the RZ/A family of regulators of G-protein signaling. Semin Cell Dev Biol 17: 390-399, 2006.

16. Wang J, Ducret A, Tu Y, Kozasa T, Aebersold R and Ross EM RGSZ1, a Gz-selective RGS protein in brain. Structure, membrane association, regulation by Galphaz phosphorylation, and relationship to a $\mathrm{Gz}$ gtpase-activating protein subfamily. J Biol Chem 273: 26014-26025, 1998

17. Huang G, He X and Wei XL: IncRNA NEAT1 promotes cell proliferation and invasion by regulating miR-365/RGS20 in oral squamous cell carcinoma. Oncol Rep 39: 1948-1956, 2018.

18. Riker AI, Enkemann SA, Fodstad O, Liu S, Ren S, Morris C, Xi Y, Howell P, Metge B, Samant RS, et al: The gene expression profiles of primary and metastatic melanoma yields a transition point of tumor progression and metastasis. BMC Med Genomics 1: 13, 2008

19. Li Q, Jin W, Cai Y, Yang F, Chen E, Ye D, Wang Q and Guan X: Regulator of $G$ protein signaling 20 correlates with clinicopathological features and prognosis in triple-negative breast cancer. Biochem Biophys Res Commun 485: 693-697, 2017.

20. Li G, Wang M, Ren L, Li H, Liu Q, Ouyang Y, He L and Li F: Regulator of $\mathrm{G}$ protein signaling 20 promotes proliferation and migration in bladder cancer via NF- $\kappa \mathrm{B}$ signaling. Biomed Pharmacother 117: 109112, 2019.

21. Yang L, Lee MM, Leung MM and Wong YH: Regulator of G protein signaling 20 enhances cancer cell aggregation, migration, invasion and adhesion. Cell Signal 28: 1663-1672, 2016.

22. Li J, Hu L, Liu Y, Huang L, Mu Y, Cai X and Weng C: DDX19A senses viral RNA and mediates NLRP3-dependent inflammasome activation. J Immunol 195: 5732-5749, 2015.
23. Livak KJ and Schmittgen TD: Analysis of relative gene expression data using real-time quantitative PCR and the 2(-Delta Delta C(T)) method. Methods 25: 402-408, 2001

24. Yao X, Hu W, Zhang J, Huang C, Zhao H and Yao X: Application of cAMP-dependent catalytic subunit $\beta$ (PRKACB) low expression in predicting worse overall survival: A potential therapeutic target for colorectal carcinoma. J Cancer 11: 4841-4850, 2020.

25. Subramanian A, Kuehn H, Gould J, Tamayo P and Mesirov JP: GSEA-P: A desktop application for gene set enrichment analysis. Bioinformatics 23: 3251-3253, 2007.

26. Chen H, Xu J, Hong J, Tang R, Zhang X and Fang JY: Long noncoding RNA profiles identify five distinct molecular subtype of colorectal cancer with clinical relevance. Mol Oncol 8 : 1393-1403, 2014

27. Kapoor A, Yao W, Ying H, Hua S, Liewen A, Wang Q, Zhong Y, Wu CJ, Sadanandam A, Hu B, et al: Yapl activation enables bypass of oncogenic kras addiction in pancreatic cancer. Cell 179: 1239, 2019

28. Xu ZY, Zhao M, Chen W, Li K, Qin F, Xiang WW, Sun Y, Wei J, Yuan LQ, Li SK and Lin SH: Analysis of prognostic genes in the tumor microenvironment of lung adenocarcinoma. PeerJ 8: e9530, 2020.

29. Yuan Q, Sun N, Zheng J, Wang Y, Yan X, Mai W, Liao Y and Chen X: Prognostic and immunological role of FUN14 domain containing 1 in pan-cancer: Friend or foe? Front Oncol 9: 1502, 2020.

30. Hurst JH and Hooks SB: Regulator of G-protein signaling (RGS) proteins in cancer biology. Biochem Pharmacol 78: 1289-1297, 2009.

31. Hurst JH, Mendpara N and Hooks SB: Regulator of G-protein signalling expression and function in ovarian cancer cell lines. Cell Mol Biol Lett 14: 153-174, 2009.

32. James MA, Lu Y, Liu Y, Vikis HG and You M: RGS17, an overexpressed gene in human lung and prostate cancer, induces tumor cell proliferation through the cyclic AMP-PKA-CREB pathway. Cancer Res 69: 2108-2116, 2009

33. Wiechec E, Overgaard J and Hansen LL: A fragile site within the HPC1 region at 1q25.3 affecting RGS16, RGSL1, and RGSL2 in human breast carcinomas. Genes Chromosomes Cancer 47: 766-780, 2008

34. Fang G, Yu H and Kirschner MW: The checkpoint protein MAD2 and the mitotic regulator CDC20 form a ternary complex with the anaphase-promoting complex to control anaphase initiation. Genes Dev 12: 1871-1883, 1998.

35. Brown NR, Lowe ED, Petri E, Skamnaki V, Antrobus R and Johnson LN: Cyclin B and cyclin A confer different substrate recognition properties on CDK2. Cell Cycle 6: 1350-1359, 2007.

36. Zou H, McGarry TJ, Bernal T and Kirschner MW: Identification of a vertebrate sister-chromatid separation inhibitor involved in transformation and tumorigenesis. Science 285: 418-422, 1999.

37. Rajurkar M, Dang K, Fernandez-Barrena MG, Liu X, Fernandez-Zapico ME, Lewis BC and Mao J: IKBKE is required during KRAS-induced pancreatic tumorigenesis. Cancer Res 77: 320-329, 2017.

38. Yang W, Qu Y, Tan B, Jia Y, Wang N, Hu P and Wang J: Prognostic significance of preoperative IKBKE expression in esophageal squamous cell carcinoma. Onco Targets Ther 11: $1305-1314,2018$

39. Wang X, Teng F, Lu J, Mu D, Zhang J and Yu J: Expression and prognostic role of IKBKE and TBK1 in stage I non-small cell lung cancer. Cancer Manag Res 11: 6593-6602, 2019.

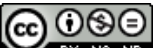

This work is licensed under a Creative Commons

Attribution-NonCommercial-NoDerivatives 4.0 International (CC BY-NC-ND 4.0) License. 